\title{
Institutional Portals
}

A Review of Outputs

\author{
Liz Pearce \\ 1 \\ $26 / 06 / 03$ \\ Work Package 3, Deliverable 1
}

the PORTAL project is funded under

the FAIR Programme of the Joint Information Systems Committee
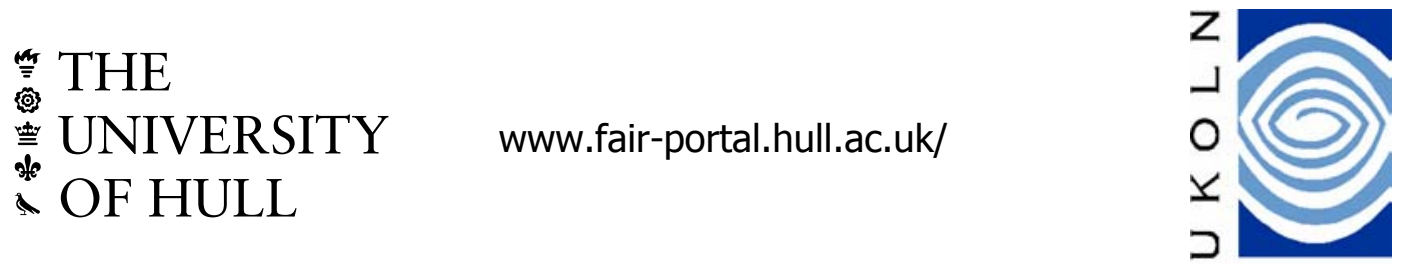


\section{Acknowledgements}

The PORTAL project is funded under the FAIR Programme of the Joint Information Systems Committee (JISC).

The project is undertaken as a partnership between Academic Services Interactive Media at the University of Hull and UKOLN, based at the University of Bath.

For further information on the JISC and JISC Programmes, visit their Web site at http://www.jisc.ac.uk/.

For further information on Academic Services Interactive Media, visit their Web site at http://www. acsweb.hull.ac.uk/imedia/.

For further information on UKOLN, visit their Web site at http://www.ukoln.ac.uk/.

For further information on the PORTAL project itself, visit the project Web site at http://www.fair-portal.hull.ac.uk/. 


\section{Table of Contents}

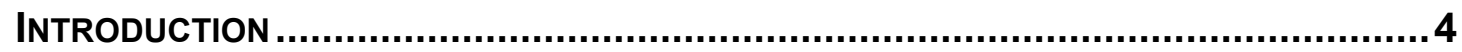

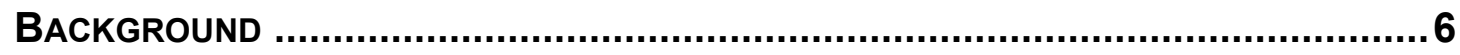

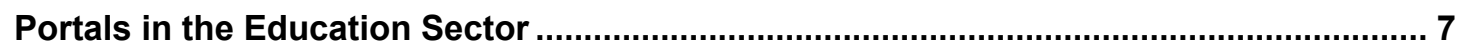

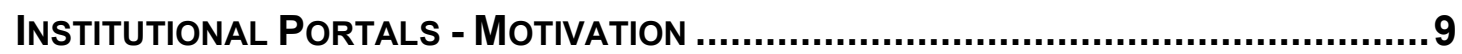

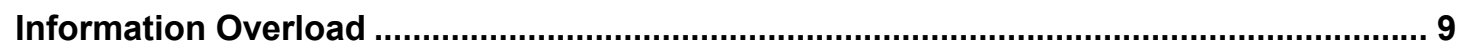

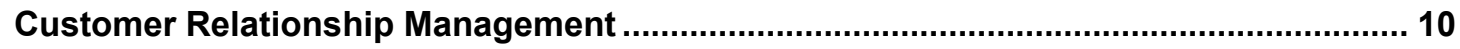

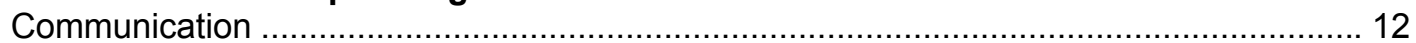

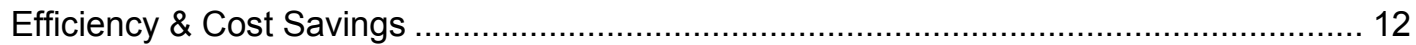

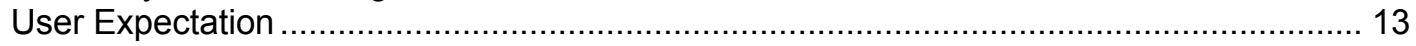

DEVELOPMENT ................................................................................... 14

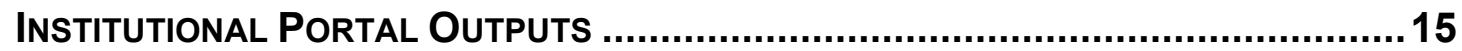

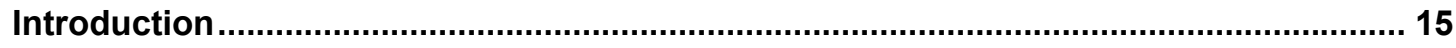

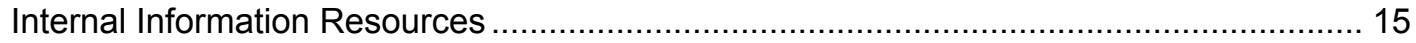

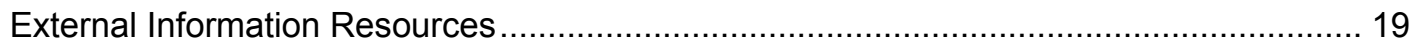

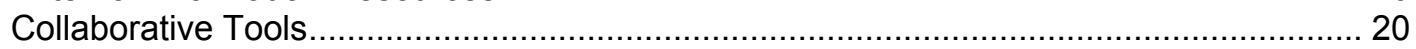

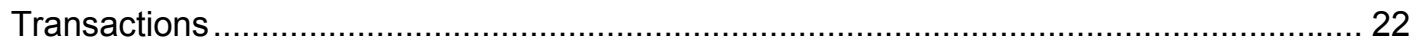

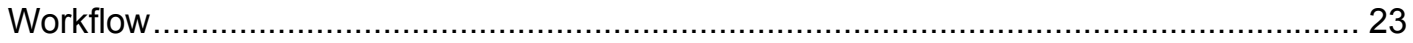

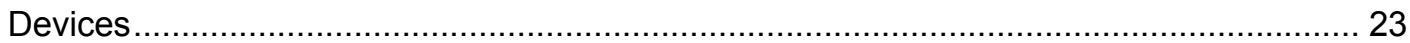

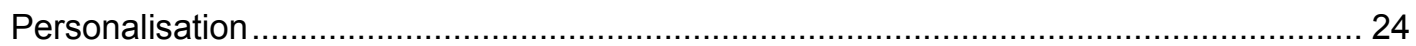

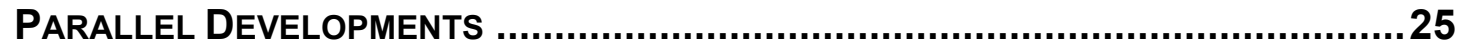

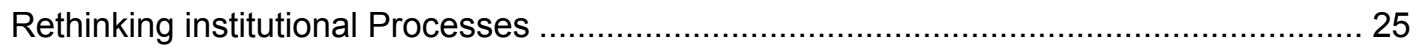

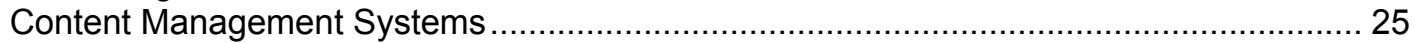

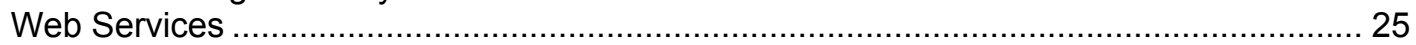

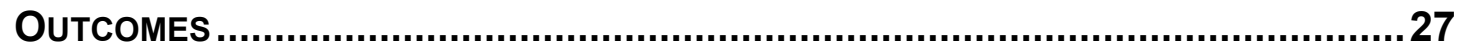

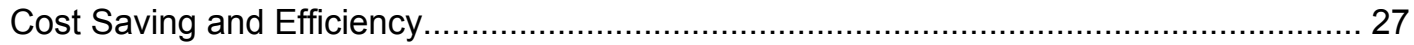

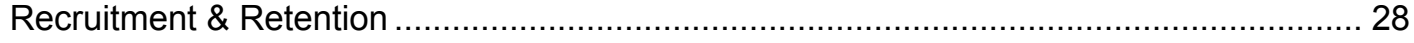

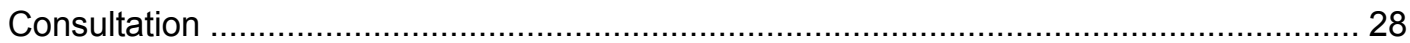

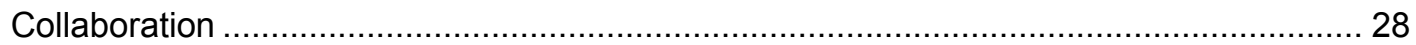

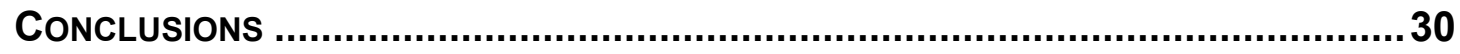

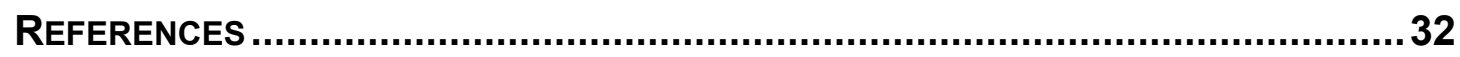




\section{Introduction}

This literature review aims to provide readers new to institutional portals with an introduction to the topic and an overview of outputs from a number of institutional portal activities. The report looks at the motivating factors surrounding the deployment of portal solutions, the outputs of existing deployments and the potential outcomes of such developments.

The review does not aim to be comprehensive and the institutions and features referenced are included as examples of developments to date rather than as a definitive set. Where possible freely available documentation has been referenced enabling readers to follow up citations where relevant. Accompanying this document is a 'Portal Function Table', which provides a snapshot of the functions included in a selection of institutional portals worldwide. The table can be accessed at http://www.fair-portal.hull.ac.uk/downloads/PortalFunction.xls

Additional institutions and details will be updated throughout the course of the PORTAL project.

The JISC Information Environment Strategy has, as a major strand, the Portals and Fusion Programme. This strand reflects the growth in interest in portals by the national funding councils and the community in general. One aspect of the Portals and Fusion Programme is

"To have a fully developed view of the nature and role of portals within the Information Environment."

Much of the current and forthcoming work within this programme of activity looks at the development of subject, audience and format based portals. The Subject Portals Project ${ }^{1}$, the User Requirements Study for a Moving Picture and Sound Portal ${ }^{2}$ and the Image Portal Demonstrator ${ }^{3}$ will undoubtedly provide the community with both increased access to content and insights into the potential and limitations of portal development. Running in parallel with these activities is the development of portals by individual institutions. Whilst institutional developments are distinct from the JISC Information Environment, developing an understanding of institutional portal outputs will assist the funding bodies in developing an integrated view of the UK education information landscape. The aim of this literature review is to illuminate the issues

\footnotetext{
${ }^{1}$ The Subject Portals Project http://www.portal.ac.uk/spp

${ }^{2}$ User Requirement Study for a Moving Image and Sound Portal http://www.jisc.ac.uk/index.cfm?name=funding_9_02

${ }^{3}$ Image Portal Demonstrator http://www.jisc.ac.uk/index.cfm?name=funding_10_02
} 
PORTAL - Institutional Portals - A Review of Outputs

surrounding the depolyment of institutional portals and in doing so to contribute to the development of this view. 


\section{Background}

Interest in portals within the corporate sector has been developing in recent years.

Strauss notes the burgeoning 'portalization' of the corporate sector, where companies:

"are rushing to produce portalware and portal-like Web pages without fully understanding the scope of a portal undertaking .... er even really understanding what a Web portal is or should do" (Strauss, 2002:33)

As a consequence, the number of websites providing links directories and limited ecommerce functions describing themselves as 'portals' has increased. The trend toward the development of corporate portals is set to continue and it is estimated that the application integration, middleware and portals market will be worth approximately $\$ 10.5$ billion by 2006 (Karpinski, 2002). In his 2001 literature review of corporate portals Dais notes that a range of portal definitions exist, each provided by a vendor stressing their own products' benefits. More recently IBM have indicated that this proliferation of definitions has stabilized and that leading groups in the field - such as Delphi, Gartner and Meta Group, are reaching a consensus. For IBM, portals provide:

"a secure, single point of interaction with diverse information, business processes and people personalised to a users need and responsibilities" (IBM, 2003)

The concept of role based information and services, from heterogeneous sources provided through a secure single access point runs through a number of portal definitions. The 'Provost on Portals' site (Eisler, Mehaffy \& Gilbert, 2000), which provides a useful introduction to institutional portal issues, offers the view that portals provide

- a single integrated point for useful and comprehensive access to information, people, and processes

- a personalized and customized user interface

Recent Accenture research (Englert, 2003) indicates that portal characteristics include:

- a gateway that provides a single point of entry to information and tools

- Web-based aggregation point

- Targeted user groups

- "My" homepage

- Easy

- Accessible from anywhere, anytime

The UK Joint Information Systems Committee echoes these definitions in their Information Environment Architecture: 
"A portal is an online service that provides a personalised, single point of access to resources that support the end-user in one or more tasks (resource discovery, learning, research, buying plane tickets, booking hotel rooms, etc.). The resources made available via a portal are typically brought together from more than one source" (JISC, 2003)

Such a definition underlines the role of the portal as a key component in the fusion, brokerage and presentation of services so key in the JISC Information Environment Strategy.

\section{Portals in the Education Sector}

Three years ago institutional portals were described as

"an emerging phenomenon that promises to revolutionize the ways universities can communicate and create community" (Eisler, Mehaffy \& Gilbert, 2000)

More recently it has been asserted that

"Although their full potential has yet to be realized, campus portals will be a part of all higher-education institutions" (Fleischman, 2002)

Global research conducted by Accenture (Englert, 2003) reflects the growing importance of portals in institutions around the world. Research was carried out with senior representatives of institutions in the UK, USA, Canada, Italy, Singapore and Australia and reveals that whilst 31 of the 47 institutions surveyed were not currently deploying a portal, three-quarters felt that they were either important or very important and $96 \%$ of the respondents were planning, developing or currently implementing an institutional portal. It is noteworthy that no participants felt that this issue was unimportant. Within the USA the '2002 Campus Computing Survey'reported that over $20 \%$ of respondents had a portal up and running in late $2002,20 \%$ indicated that their portal was under development and $30 \%$ reported that the deployment of an institutional portal was under discussion. In the UK, Information Services at the University of Bristol maintain a register of those considering, implementing or deploying portals within the UK educations sector (Browning, 2003). The growing interest in portals within the UK education sector is reflected by the large attendance at the Portals 2002 Conference held at the University of Nottingham ${ }^{4}$ and the oversubscribed UK uPortal Users Workshop held at The Deep Business Centre, Hull ${ }^{5}$. Such events have highlighted both the interest in portal development and the range of work currently underway in this area.

\footnotetext{
${ }^{4}$ http://www.nottingham.ac.uk/portals2002/

${ }^{5} \mathrm{http}: / /$ wwwfair-portal.hull.ac.uk/17nov02/
} 
Along with the specific work on 'portals' noted in the Introduction, work on Managed Learning Environments is an ongoing area of JISC activity ${ }^{6}$. At the Portals 2002 conferences Awre (2002) indicated that a Managed Learning Environment (MLE) is a system which comprises the range of information systems and processes of an institution whether they contribute directly or indirectly to learning and learning management. Awre suggests that institutional portals could be a way in which MLEs are presented to end users. Indeed, a number of current portal deployments, including COMPASS at the University of Nottingham ${ }^{7}$ and the De Montfort University portal ${ }^{8}$, were inspired, or funded, by the JISC 7/99: Managed Learning Environments programme ${ }^{9}$, reflecting the overlap of issues. The University of Nottingham COMPASS project plan indicates that a key goal of the portal development project was to provide access both to resources for scholarly endeavour and for the vital administration and management of that endeavour (Stanton, 2002). Whilst not developed as part of a $7 / 99$ project such a vision is shared by the University of Hull whose Digital University Project defines a portal as:

"A web-based layer which aggregates, integrates, personalises and presents information, transactions and applications transparently for the user according to their role and preferences." (Dolphin \& Sherratt, 2002)

The overlap between Managed Learning Environments, Virtual Learning Environments and institutional portals will be discussed in greater depth in Work Package 12 of the PORTAL project.

\footnotetext{
${ }^{6} \mathrm{http}: / / \mathrm{www} . j \mathrm{jisc} . \mathrm{ac} . \mathrm{uk} / \mathrm{index} . \mathrm{cfm}$ ?name$=\mathrm{mle}$ home

${ }^{7} \mathrm{http}: / /$ www.eis.nottingham.ac.uk/compass/

${ }^{8} \mathrm{http}: / / w w w . m l e . d m u . a c . u k$

${ }^{9} \mathrm{http}: / / \mathrm{www} . j i s c . a c . u k /$ index.cfm?name=mle_home
} 


\section{Institutional Portals - Motivation}

Top Reasons For Portal Development (Multiple Responses)

Integrate / streamline information \& services Improve service to students/staff

Offer personalized / customized / targeted service Improve administration efficiency

Attract students

Enhance university image / raise profile

Engage / connect / build community

Offer distance / flexible learning

Attract business / research partners

Maintain alumni network

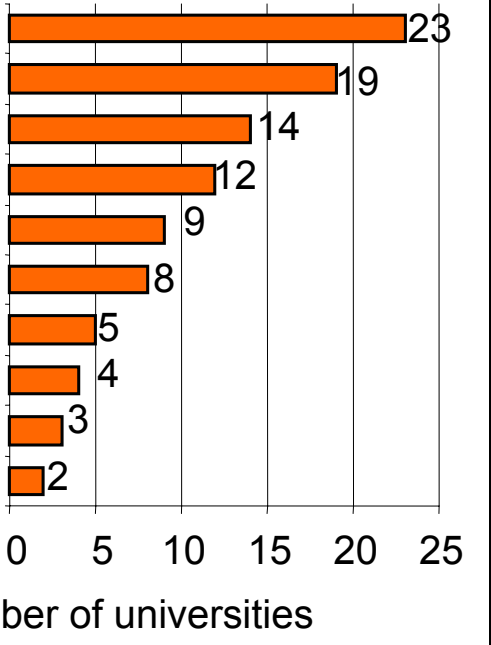

Table 1 Accenture Research - Portal Trends in Higher Education, Englert, 2003@ .

\section{Information Overload}

For a number of institutions the driving force behind the implementation of an institutional portal is the growing awareness of the impact of institutional information overload on both staff and students. Englert (2003) indicates that streamlining access to information and services and providing targeted services were popular reasons for deploying institutional portals amongst the 47 institutions surveyed in recent Accenture research (Table 1).

Many institutions provide access to institutional information via the institutional website. Given the varied roles and activities that institutional stakeholders in the education sector carry out - from managing budgets and delivering maintenance services to conducting research and educating students - it is unsurprising that the information requirements of these groups are many and varied and that when presented on mass such a range of resources leads to information overload. The University of Buffalo, for example, found that its institutional website consisted of over 250,000 pages spread over 17 institutional servers (Olsen, 2002), such a realisation led to the decision to consolidate key information and transactions within an institutional web portal.

In the UK the University of Nottingham began their Compass Project to provide an: 
"easy and coherent route through to all the online information and services relevant to their [students] life" (EIS University of Nottingham 2002)

The emphasis on both 'easy' and 'coherent' reflects a need to counter the often baffling array of information available. Olsen (2002) reveals that one - nameless - institution's website review exposed the fact that tuition fees appeared on six of the institutions 100,000 webpages and that each page cited a different figure. Whilst the overabundance of institutional information is one reason for deploying an institutional portal it is clear that institutional stakeholders also require access to coherent services and resources. Eisler (2001) indicates the extent to which technical development has enabled portal technology to address the issue of both information overload and coherence:

"portal technology is driven by innovation in two primary functions: search / navigation and personalisation .... portal can help address to fundamental challenges facing users today, the overabundance and discontinuity of information" Eisler, 2001

For Looney \& Lyman (2000) portals, even at the most basic level, can help combat 'infoglut' and prevent users feeling 'lost on the web', the authors refer to portals as a 'home on the web' a place to return to make sense of necessary information.

\section{Customer Relationship Management}

For Katz (2002) building relationships between institutional constituent groups is a primary task of institutional portals

"the new, wonderful and challenging aspect of Web management posed by portals is the idea of creating and managing information systems whose primary purpose is to sustain positive relationships between an institution's stakeholders and the institution" (Katz, 2002:8)

Two of the ten chapters in 'Web Portals and Higher Education'(Katz et al, 2002) focus explicitly on 'customer relationship management' (Grant \& Anderson, 2002) and 'customer centred resources' (Lightfoot \& Ihrig, 2002). Indeed, Lightfoot and Ihrig use the phrase 'relationship manager' interchangeably with the word 'portal'. A number of portal developments are viewed in terms of customer service development, for example the University of Delaware indicate that the portal provides a tool for managing relationships with 'customers' (Jacobson) and Connelly (2000) refers to the portal providing easier access for Villanova 'customers'. Whilst the term 'customer' has connotations of the commercialisation of education the 'customer' in these scenarios is not the student paying for the courses, though they form an important stakeholder group, but the teaching staff, researchers and parents and employers who are the recipients of institutional information and users of institutional services and resources. 
The view of stakeholders as 'customers' encompasses both the financial and the community building aspects of customer service development and management. The focus on relationship management in portal development is perceived to translate into increased revenue through recruitment and retention as a result of improved customer service and satisfaction. Looney \& Lyman (2000) highlight the potential of institutional portals to both develop and maintain institutional communities:

"We believe that the value of a portal to a campus is that it can be used to engage constituent groups, empower them with access to information resources and communication tools, and ultimately retain them by providing a more encompassing sense of membership in an academic community." Looney \& Lyman (2000)

The authors indicate that many of the key questions when planning portals are concerned with building communities beyond the campus walls, fostering application, acceptance and retention rates and increasing the quality of alumni and parent relationships. More recently McCredie (2002) has indicated that fostering institutional community beyond the campus and meeting customer requirement has remained central to developments at the University of California Berkeley.

In the UK the commitment to customer service shaped the development of the London School of Economics' 'LSE for You'10. Cobb, Riley and Earley (2002) note the incongruity between the high numbers of overseas students applying to the School and the standard UK office hours and public holidays observed by the institution. In order to foster a sense of identification with the institution through the deliver of effective services to applicants the institution developed a portal to provide $24 \times 7$ access to information and services.

Eisler (2001) notes that portals

"offer the prospect of helping higher education find new ways to connect with students, faculty, alumni and the community ... many colleges strongly feel the need to create new avenues for building community among their people"

The creation and maintenance of an institutional community was central to the development of GWeb at George Washington University ${ }^{11}$, where the institution was keen to replicate and develop the University's sense of community in an online environment. The University noted, with concern, students using external sites - such as Yahoo and AOL - for information and communication and as a result much of the portal effort has centred on getting users to return to institutional sites and services (Olsen, 2002).

\footnotetext{
${ }^{10}$ London School of Economics, LSE for You https://lfy.lse.ac.uk/forwardrequest.html?url=http://lfy.lse.ac.uk/mylse/xhtml/welcometomylse.html

${ }^{11}$ George Washington University, GWeb Portal http://gweb.gwu.edu/
} 
For Jacobson providing resources for communities, be they campus wide, department or interest based, is as fundamental to the development of portals as personalisation. For him

"'Personalization' and "community" are two of these tailoring methods, and they are the backbone and nervous system of an institutional information portal." Jacobson (2000)

Jacobson indicates the potential dangers associated with individual departments and courses developing their own portals. He notes that institutional communities can be further fractured and fragmented by such developments which merely maintain silos of campus information and processes. The avoidance of institutional 'Portal wars' (Browning, 2002) requires clear institutional support and buy-in for portal developments.

\section{Communication}

The desire for effective communication within and between constituent groups has also been a motivation in the development of institutional portals. George Washington University rate the enabling of 'agile' institutional communication as a key challenge in the development of their portal (de Leo, 2002). Similarly, the University of British Columbia wanted to end 'batch communications' by replacing mass email with the delivery of flexible targeted information for specific groups or individuals (Olsen, 2002). As indicated the implementation of communication tools and the creation of a single point of institutional communication can be seen as key elements in creating campus communities and tackling information overload.

\section{Efficiency \& Cost Savings}

Whilst it is clear that institutions are motivated to deploy portals by a range and combination of the factors for Pickett and Hamre

"there is one major reason for portals, efficiency. Portals help make more efficient use of an individual's time" (2002)

Similarly, for Looney and Lyman institutional portals are designed to make the users

"Web experience more efficient and thereby make the institution as a whole more productive and responsive" (Looney and Lyman, 2000) .

Such a perspective is shared by Connelly (2000) who indicates that taking advantage of the portal to create an individualised information repository can lead to administrative cost savings and easier access for users. At the University of California Berkeley, senior staff realised that in a time of recession the federal agencies would be unwilling to provide additional funding for higher education. With a non academic workforce of over 
100,000 the efficiency gains created through providing personalised access to information and services online are potentially large (Regents of the University of California, 2002). Louisiana State University's desire to provide all members of the institutional community with access to data previously only available through administrative offices led to the development of a portal which provided access to existing systems (Etheridge, Hadden \& Smith, 2000). By empowering the user to access systems directly staff were able to work more efficiently and students access data more easily. Within the UK Supple (2003) indicates that tackling the increased workload burden of academic staff and creating administrative efficiency gains were drivers behind the decision to deploy a portal at the University of Birmingham. Similarly Cobb, Riley \& Earley report that the development of 'LSE for You' aimed to reduce the duplication and expense of keeping users informed my traditional methods

"It was labour intensive and costly to keep customers informed: letters were produced from different service providers for different purposes and little effort was made to coordinate postings between offices" (2002)

Whilst a number of institutions indicate that efficiency gains and cost savings were a motivating factor in the development of their portals, Englert (2003) notes that within Accenture's global research they were not the primary motivator at a significant number of sites.

\section{User Expectation}

User expectations both of technology and customer service standards have shaped the deployment of portal at various institutions. Lightfoot and Ihrig (2002) note that

"the new breed of technology savvy students ... demand a higher level of access to information about their options, their performance and their future"

Similarly, Walsh \& Thomas (2002) note that in an age of 'disintermediation' students often expect to be able to carry out transactions and locate information for themselves. Cobb, Riley and Earley (2002) indicate that part of the impetus for the creation of LSE for You was to meet increased customer expectations by increasing the quality of customer services. 


\section{Development}

Having established the need for institutional portal development, institutions are faced with the choice of how to deploy a portal. There are a number of portal vendors providing systems to the higher education community, a number of institutions have decided to develop their own portals whilst others have chosen to participate in collaborative efforts like the Java Architectures Special Interest Group's uPortal development ${ }^{12}$.

San Diego State University developed a Rubric for Rating Commercial Portal Vendors (Frazee, 2001). The rubric deals with elements from aesthetics and ease of use to pricing and security. The San Diego State University rubric has been used as the basis for portal selection at the University of Hull and the University of Bristol, amongst others.

Whilst the initial choice for institutions appears to be 'Buy or Build' Englert (2003) notes that most institutions are doing a combination of the two and, perhaps indicating a future trend, that half of the respondents to Accenture's survey would be willing to outsource their portal deployments.

\section{Development Challenges}

In his list of challenges facing portals developers Englert (2003) identifies obtaining 'buy-in' for developments from diverse stakeholders as the number one challenge facing portal developers, followed by integrating legacy systems and financial considerations. Whilst technical and financial constraints will undoubtedly influence portal deployments, a number of authors consider human factors to be key to the success of portal developments. Katz (2002) notes that

"[portal] strategy is difficult and perilous because many on campus are weary and suspicious of yet another new enterprise-wide information technology initiative... portal initiatives, by definition, require across-the-institution agreement ...that are hard to achieve in loosely coupled organisations like academic institutions"

Similarly Gleason (2002) indicates that senior institutional stakeholders will want to see working systems rather than the 'conceptual design' required for thorough portal development planning.

\footnotetext{
${ }^{12}$ Java Architectures Special Interest Group uPortal http://mis105.mis.udel.edu/ja-sig/uportal/
} 


\section{Institutional Portal Outputs}

\section{Introduction}

The outputs of institutional portal developments are varied. The JISC definition of an institutional portal describes the various features as belonging to three categories access to information resources (internal or external), transaction-based services and collaborative tools:

"An institutional portal provides a personalised, single point of access to the online resources that support members of an institution in all aspects of their learning, teaching, research and other activities. The resources may be internal or external and include local and remote 'information resources' (books, journals, Web-sites, learning objects, images, etc.), 'transaction-based services' (room bookings, finance, registration, assignment submission, assessment, etc.) and 'collaborative tools' (calendars, email, chat, etc.). Typically, access to many of these resources is restricted to authenticated members of the institution" (JISC, 2003)

The features highlighted in this section reflect the range of functionality developed within institutional portals and have been described under JISC's categories. Examples have been drawn from a number of institutions and are not intended to be comprehensive.

\section{Internal Information Resources}

As indicated, ensuring ease of access to coherent institutional information is a key motivating factor in institutional portal developments. The range of internal information resources presented via portals reflects the perceived value of such services to users.

\section{Institutional News}

The use of the institutional portals to enable stakeholders to access timely and relevant information about their institution is one of the most popular aspects of portal development. Many institutions, including the University of Stanford ${ }^{13}$, the University of Delaware ${ }^{14}$ (Figure 5), the University of Nottingham, and CalPoly ${ }^{15}$ provide users with access to campus news via channels on their main portal page. Dynamic news feeds are frequently created using RSS (RDF Site Summary) channels. Moving beyond the textual focus of most portal content GWeb at George Washington University includes live broadcasts from the campus radio station alongside its text based campus news service. Another popular way to disseminate internal information is via personalised institutional announcements such as the 'Personal Notifications' feature provided by

\footnotetext{
${ }^{13} \mathrm{http}: / /$ my.stanford.edu

${ }^{14} \mathrm{http}$ ://uportal.udel.edu/student

${ }^{15} \mathrm{http}: / /$ my.calpoly.edu/index.jsp
} 
UCLA $^{16}$ and the 'My Campus Messages' feature provided by the University of California Davis $^{17}$ (Figure 1: third channel down, right hand side).

\section{Timetables}

Access to individual course schedules for students and staff is listed one of Olsen's (2002) 'must have' portal features. A number of institutional portal sites include access to timetables for students and staff, for example The University of California, Davis provides access to the 'My Classes' list (Figure 1: top right), the University of Wisconsin, Madison ${ }^{18}$ provides a course grid (Figure 2) and the London School of Economics provides timetable access for staff and students and an am exam timetable for students.

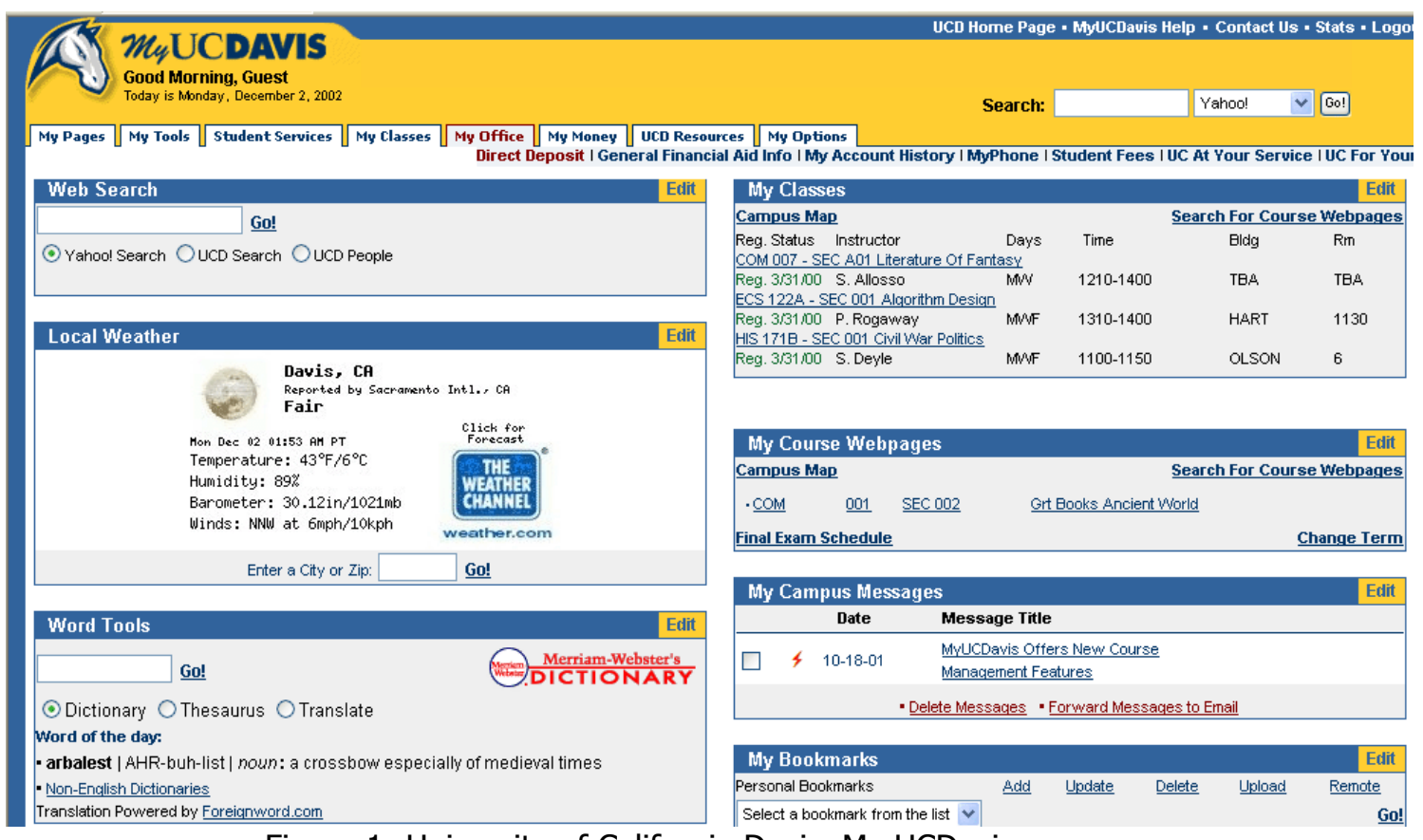

Figure 1: University of California Davis, My UCDavis.

\footnotetext{
${ }^{16} \mathrm{http}: / /$ my.ucla.edu/

${ }^{17} \mathrm{http}: / /$ my.ucdavis.edu/

${ }^{18} \mathrm{http}: / /$ my.wisc.edu/portal/
} 


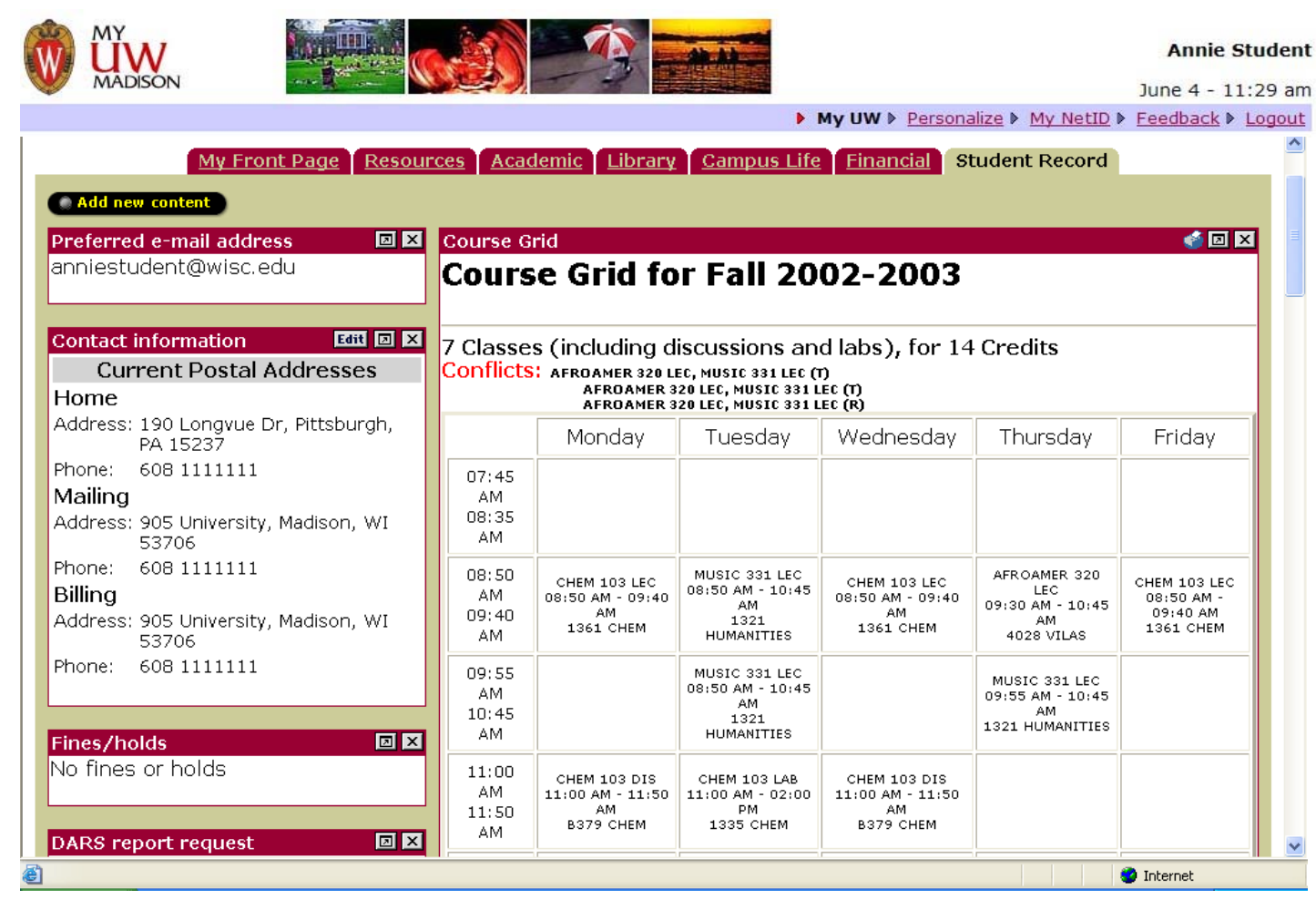

Figure 2: University of Wisconsin Madison, My UW Madison.

For users of Louisiana Statue University's 'PAWS' system access to their course listings was one of the most popular features amongst students using the system. The feature was rated, shortly after the launch of the system, a close second behind access to email systems (Etheridge, Hadden \& Smith, 2000) reflecting the popularity of scheduling information with users.

\section{Personal Information}

The provision of access to a range of personal information forms a feature of a number of institutional portals. For example the University of Wisconsin, Madison provides access to personal contact information and library fines (Figure 2: left hand column) and also provides financial status information (via the Financial tab). Similarly, the University of British Columbia ${ }^{19}$ provides users with access to their grade history, fines and fees information and library administration and the University of Hull ${ }^{20}$ provides student users with the ability to check their academic history, personal and contact details (Figure 3).

Providing users with access to the information which institutions hold about them is a common portal feature and, according to Cobb, Riley \& Earley (2002) of The London School of Economics, an increasingly important one. They note that UK Data Protection legislation places an onus on institutions to ensure the accuracy of data and provide

\footnotetext{
${ }^{19} \mathrm{http}: / /$ my.ubc.ca/render.userLayoutRootNode.uP

${ }^{20} \mathrm{http}: / /$ port.hull.ac.uk
} 
data subjects with access to the information held about them. 'LSE for You' provides users with the ability to view their contact and academic information along with their financial account status, their payslip details (for staff) and enables postgraduate applicants to check on the status of their application.

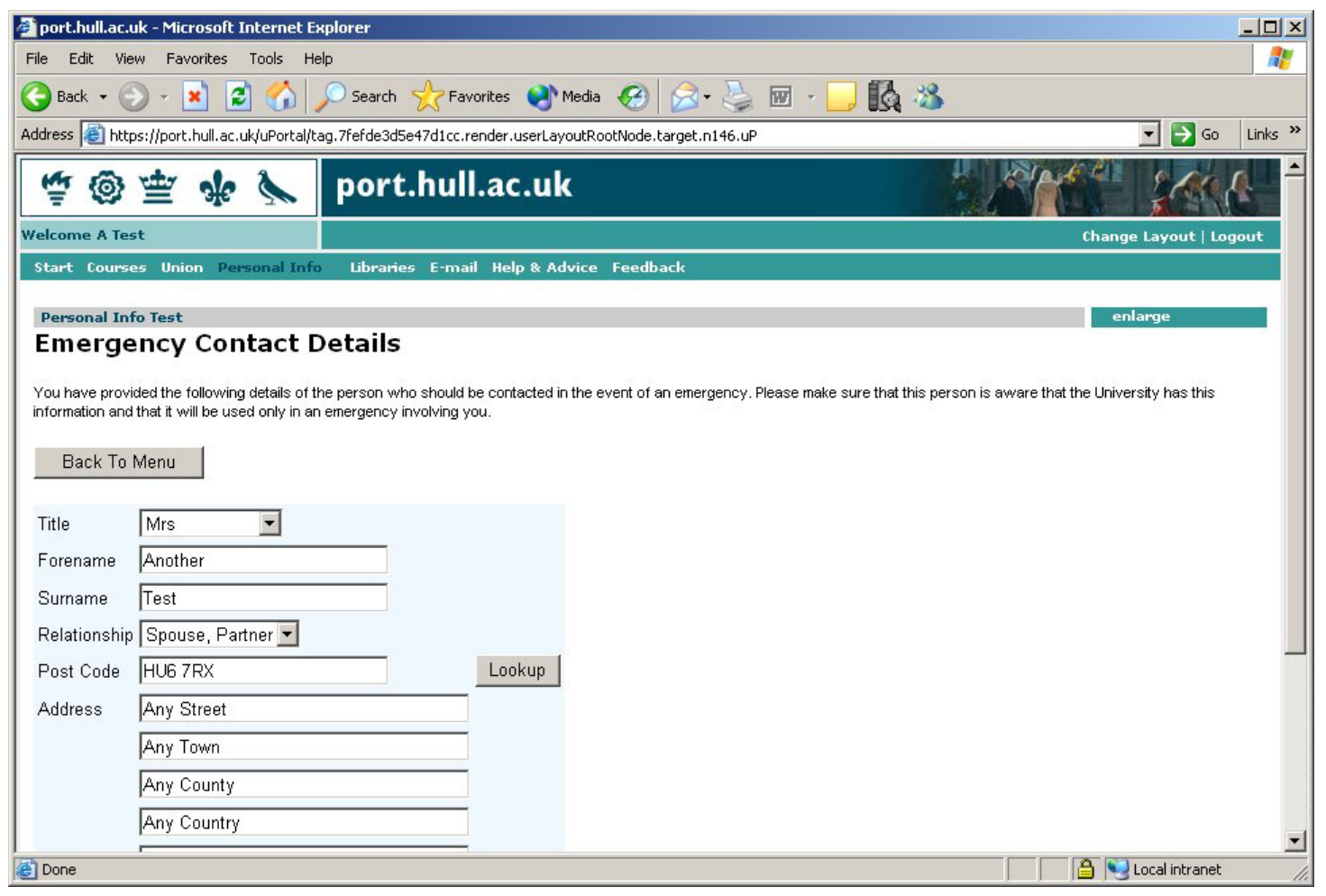

Figure 3: The University of Hull, port.hull

\section{Course Materials}

A number of portals have sought to provide access to course materials. Features such as the Louisiana State University's PAWS Semester Book (Etheridge, Hadden \& Smith, 2000), Villanova's 'MyClassroom feature (Connolly, 2000) and Santa Barbara City College's 'My Courses: Class Links' function (the latter two of which were the top rated their respective institutions top rated portal features) provide students with course materials, internet resources and other course related information. Where institutions are deploying Virtual Learning Environments / Learning Management Systems to deliver course materials to students both licensing and technical issues exist around integrating such systems into institutional portals. Further discussion of the issues surrounding MLEs / VLEs and institutional portals will be provided by Work Package 12 of the PORTAL project. 


\section{External Information Resources}

\section{Sticky Features}

A variety of external information resources are often included in institutional portals as 'fun' or 'sticky' features; these include cartoons, web search boxes, maps, dictionaries, local and national news, local weather and travel information. The majority of institutional portals include at least one these features. Figure 1 shows the inclusion of a web search box, weather information and an online dictionary at the University of California Davis.

\section{Customisable Links}

A number of institutional portals also enable users to add and manage their own internet links. For example, My UCDavis (Figure 1, bottom right) provides users with the ability to manage their internet bookmarks via the portal and GWeb at George Washington University enables bookmarks and webnotes to be shared with other portal users.

\section{Library and Quality Internet Resources}

Whilst a number of institutional portals provide access to links to their institutions library pages, the University of Buffalo is one of a more limited number to include meaningful access to library information and resources. The MyUB portal ${ }^{21}$ (Figure 4) provides links to both library catalogues and homepages and also directs users to subject resource pages relevant to their major, in this case Maths and Engineering, and to the contact details of their library subject specialist.

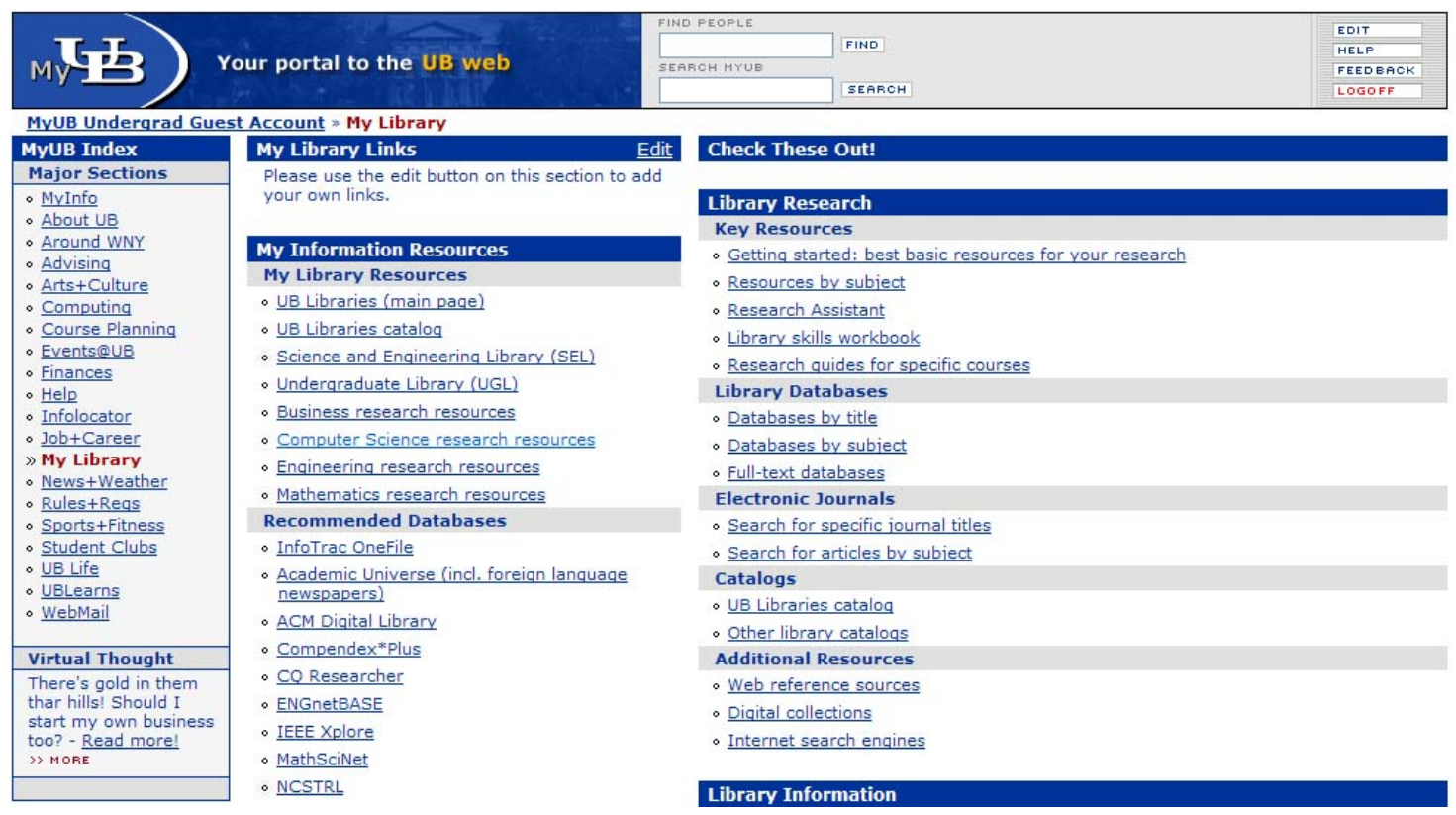

\footnotetext{
${ }^{21} \mathrm{http}: / /$ www.buffalo.edu/aboutmyub/
} 
Figure 4: University of Buffalo, MyUB

Technical work ongoing within the PORTAL project is looking at the meaningful integration of external resources within an institutional portal framework.

\section{Collaborative Tools}

\section{Communication Tools}

Another of Olsen's (2002) 'must have' portal features is access to web based email. Email services are included in a number of institutional portals. Both Santa Barbara City College (Campus Pipeline, 2002) and Louisiana State University (Etheridge, Hadden and Smith, 2000) indicate that access to email has proved to be highly popular with students. Institutions such as Villanova University and the University of Wisconsin Madison provide users with an 'at a glace' view of the number of new email messages they have via a portal channel on the main portal page.

The inclusion of the communication tools can also prove vital in maintaining communities beyond the institution. At the London School of Economics alumni were encouraged to continue using their LSE account via the portal in order to maintain a strong community and LSE identity.

Another communication tool which proved successful in establishing student stakeholder buy-in for George Washington University's portal was the integration of various instant messenger services. Students can send and receive instant messages via the portal regardless of the messaging service they use. Having established student stakeholder buy-in the George Washington University portal is now key to the delivery of departmental news and the system has become the major means of communication and collaboration with over 18,000 users (Olsen, 2002).

Discussion fora are often included in institutional portals as either informal communication areas for users, such as at UCLA where the institution takes no responsibility for the content of postings, or within a learning context. Villanova's My Classroom feature and Louisiana State University's PAWS Semester Book deploy email lists and discussion groups as part of an online collaborative learning environment.

\section{Specialised Postings}

Message boards and other asynchronous communication features have been deployed to various ends at a number of institutions. For example, the University of Delaware ${ }^{22}$ (Figure 5, bottom right) and George Washington University provided classifieds channels and Louisiana State University provides access to ride share notices.

\footnotetext{
${ }^{22}$ http://uportal.udel.edu/student/
} 


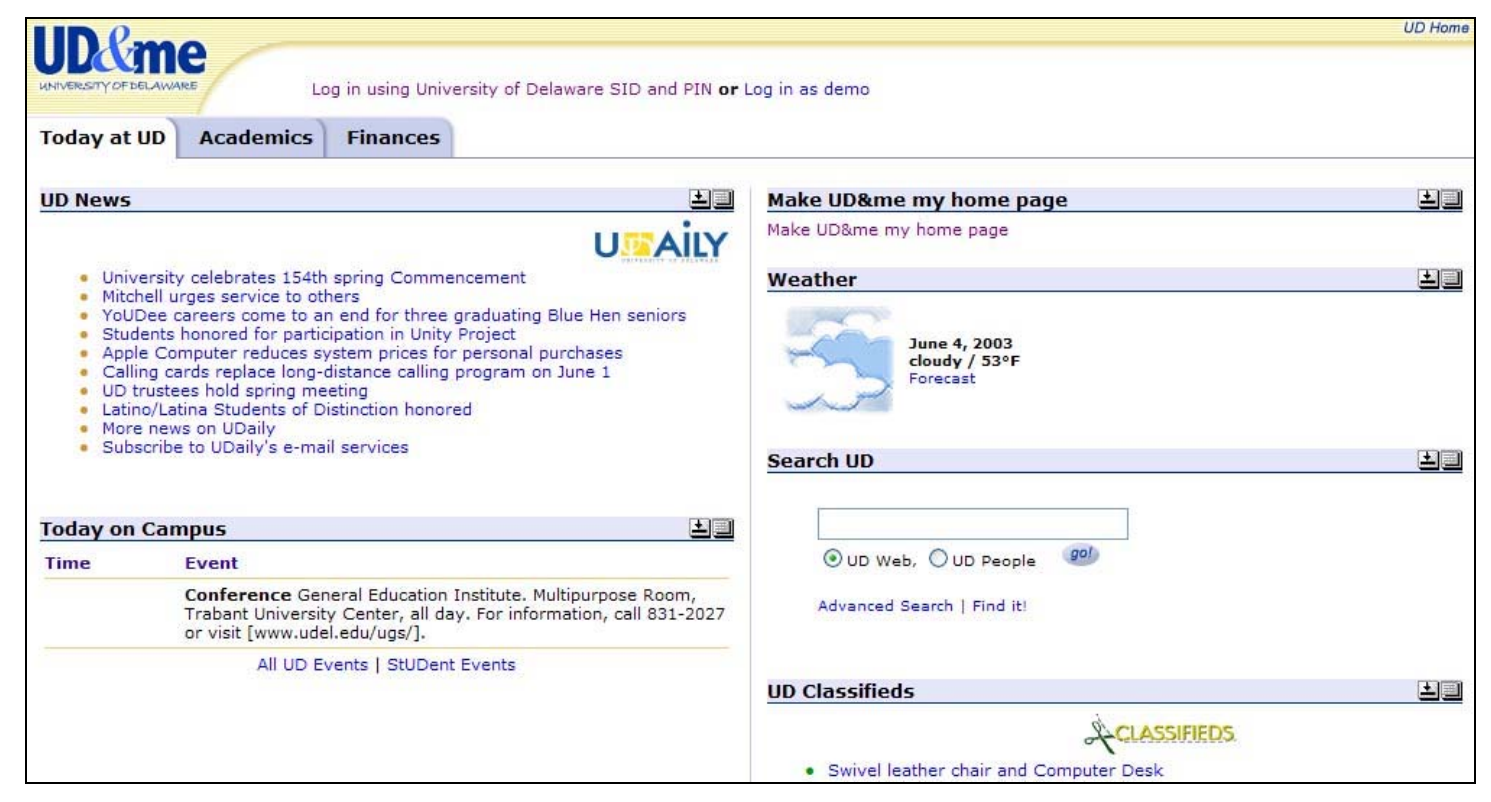

Figure 5: University of Delaware, UD\&Me

\section{Calendar}

In the course of conducting this review it became clear that measuring the outputs of institutional portals was a far from easy task. A seemingly simple function such as providing a 'calendar', which is categorized as a collaborative tool in the JISC definition, produced a number of different manifestations. For some institutions the calendar provides access to university events, such as the 'Today on Campus' channel included in The University of Delaware's UD\&Me (Figure 5), for others class schedules and timetables made up the staff and student calendar system. Similarly calendars were static at some sites and could be personalised, added to and shared at others. The standard institutional almanac is available via a number of institutional portals and a number had enhanced such resources with additional features. For example, the University of Illinois iCampus ${ }^{23}$ provides students with access to a calendar of university events, 'to do' lists and enables them to add personal appointments to their own calendar (Fleischman, 2002). The University of Washington Calendar project ${ }^{24}$ is an ongoing activity looking to provide a modular calendar providing personal, public and group calendar applications. Figure 6 illustrates the searchable calendar of campus events, academic and events calendars for various campuses and events in particular areas.

\footnotetext{
${ }^{23} \mathrm{https}$ ://www.icampus.ilstu.edu/

${ }^{24} \mathrm{http}: / /$ www.washington.edu/ucal/index.html
} 


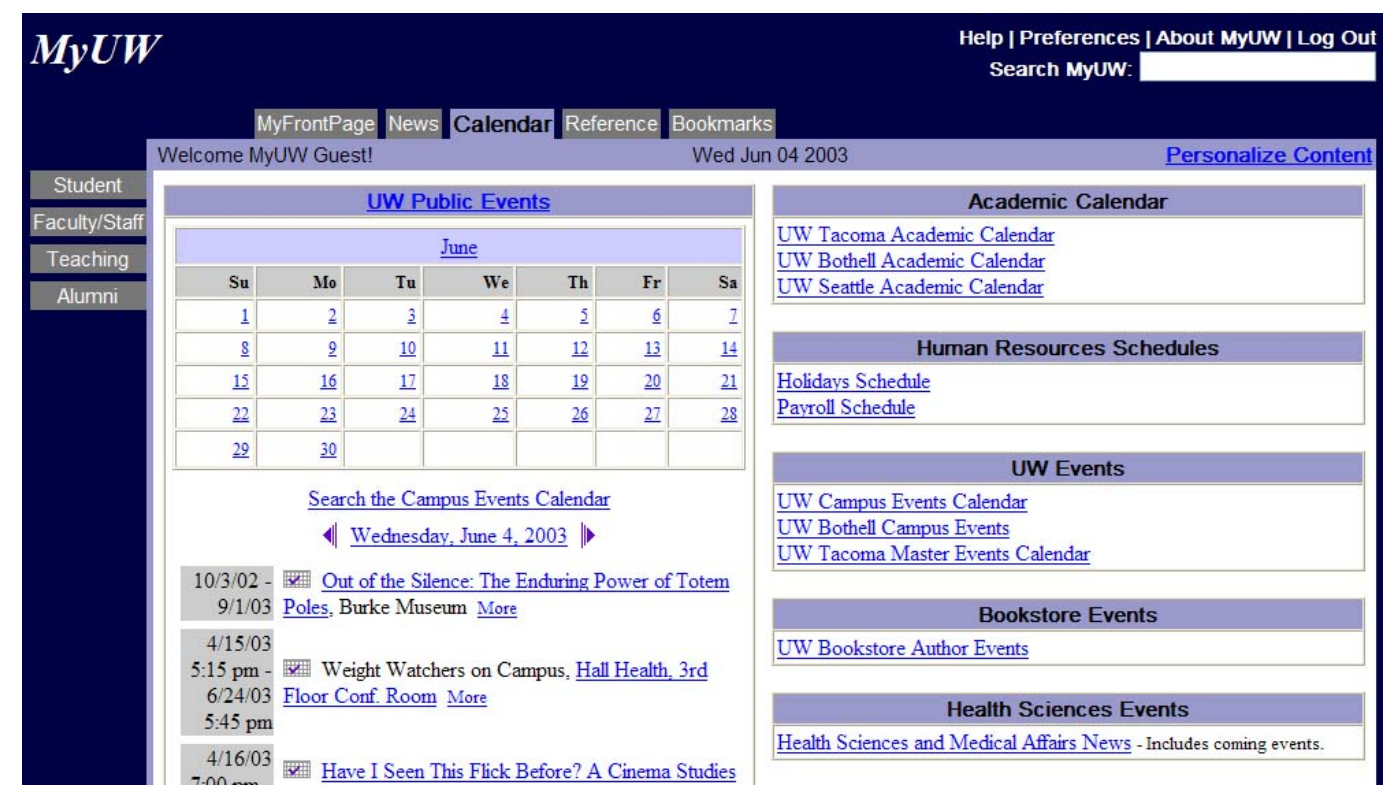

Figure 6: University of Washington, MyUW

\section{Feedback}

The majority of institutional portal sites provide access to user feedback mechanisms regarding institutional issues or the portal itself via an email link. George Washington University have deployed polling mechanisms within the portal to enable users to contribute their views about both institutional and international issues. For example, at the time of writing GWeb was running a poll regarding the name of the University's email client, over 600 users had registered their views, previous polls have included 'How did you learn about the new Gweb Portal?' and 'What did you think of online voting in recent student elections?'.

\section{Transactions}

The Provosts on Portals site indicates the potential of portals for providing transactional services.

"Portals that are integrated into university back-office operations can become a one-stop interface for educational transactions over the web" Eisler, Gilbert \& Mehaffy, (2001)

Two years later, in the light of global research, Englert (2003) notes that institutions still have the furthest to go in terms of the transactional services they offer and claimed that:

"In the main portals are being technology led rather than user led with resources first directed to what is obvious and easy to do" Englert, 2003

Despite the difficulties of providing transactional services a number institutions are providing a range of transactional services via their portals. 'Must have' transactions 
include the ability for students to register and add and drop classes whilst a number of institutions have provided their users with the ability to apply, pay fees, select or update meal plans and parking permits via the portal. For example, Louisiana State University indicated, as early as 2000 students that:

"can conduct homecoming elections, register for classes, and select meal and parking plans." Ethridge, Hadden \& Smith (2000)

and are now able to make credit card payments on fee bills ${ }^{25}$. Similarly, the University of Buffalo offers prospective students the opportunity to both apply and pay tuition and housing online ${ }^{26}$. The London School of Economics offers the ability to access fee statements and pay fees online, choose and validate module choices, and check and make room bookings. Cobb, Riley and Earley describe how

"phone and email requests have given way to on-line forms that receive and transact data immediately, providing automated results, outcomes or confirmation." (2002)

\section{Workflow}

Pickett and Hamre (2002) indicate that managing business process workflow systems have not yet widely adopted by institutional portal developers due to the time consuming and intensive nature of the undertaking. Yet workflow is an important part of the work undertaken at Louisiana State University (Etheridge, Hadden and Smith, 2000) with web based project management tools integrated with other campus systems.

As a first step towards developing workflow systems and decision support a number of institution have aimed to provide access to relevant policies and documentation, electronic forms.

\section{Devices}

Whilst the provision of portal services and data via mobile devices has yet to become a major area of activity in institutional portal development references to it appear in a number of institutional strategies. For example the University of Wisconsin Madison's Information Technology Strategic Direction 2002 refers to the need to build on the development of the institutional web portal whilst facilitating the use of wireless and mobile technologies. Similarly, the University of Hull's Building the Digital University included planning for the increased use of PDAs and WAP enabled mobile phones. Despite many institutions being at the preliminary planning stages of such

\footnotetext{
${ }^{25} \mathrm{http}: / /$ paws004.1su.edu/paws000.nsf/

${ }^{26} \mathrm{http}: / /$ www.buffalo.edu/admissions/
} 
developments Drexel University ${ }^{27}$ has successfully 'wedded' their institutional web portal with their campus wide wireless network enabling users to access course resources, transactions and communications via a range of mobile services.

"Users who've registered their mobile devices can have relevant personal announcements pushed out to them automatically, without having to browse to find the information... students can get their grades as soon as they're posted and, learn of last minute classroom changes, get updates to their schedule" (Drexel, 2003)

Whilst such developments may be viewed as remote by many institutions the success of Drexel's initiative reflects the increasing interest, and potential demand, for such services.

\section{Personalisation}

The 'restriction to authenticated members of the institution' referenced in the JISC definition of an institutional portal has enabled institutional portals to provide access to personalised information and services. The subtleties obtainable through the effective use of personalisation are reflected in Jacobson's view of the 'uniquely tailored' institutional view.

"To provide varied views that meet the needs of a diverse user population, the gateway to this model must be a multifaceted lens-an abridged version of the institutional Web, which provides a uniquely tailored view to each user. The gateway must be an 'institutional information portal' (Jacobson, 2000).

The personalisation of information and services relies on the implementation of effective person directory information. Work Package 6 of the PORTAL project provides a view of the metadata schemas available for the description of portal users.

\footnotetext{
${ }^{27} \mathrm{http}: / /$ one.drexel.edu/cp/home/loginf
} 


\section{Parallel Developments}

\section{Rethinking institutional Processes}

The relationship between examining business and work processes and the implementation of an institutional portal varies between institutions. For some, such as the University of California Davis, what began as a student portal supporting academic function is developing and expanding its remit to meet the recommendations put forward by business process reviews (Regents of the University of California, 2001). Similarly, Supple (2003) indicates that for the University of Birmingham attention to process reengineering has been central to the planning of their portal implementation. For others portals, through exposing flawed information or process, have acted as a catalyst for institutions wide re-examinations.

\section{Content Management Systems}

The ongoing development and delivery of information and services via portals have been percieved by some writers to be one of the most problematic areas that institutions will face

"the problem is not the absence of suitable technology... we believe the bigger issues to tackle are ones that affect sustainability: content, maintenance, and support" (Looney \& Lyman, 2000: 34)

Such statements illustrate the need for content management systems to underpin the development of institutional portals. For example George Washington University use a content management system to feed departmental or organisational news and events into both the portal and university site (de Leo, 2002). Similarly the University of Hull has developed a content management system which allows those with appropriate roles to publish information both to institutional websites but also to relevant sections of port.hull, the use of style sheets has enabled the creation of WAI level 1 and 3 compliant pages for users with specialist access needs.

\section{Web Services}

The integration of heterogeneous systems and the provision of access to modular applications so vital to the success of portals are dependent on the use of appropriate standards. The emerging wed services standards have developed in parallel with portal developments. As a recently published Techwatch report indicates:

"WST (Web Services Technologies) have a number of potential application areas of specific interest to UK HE and FE. Within institutions WST will offer an economical and effective way of rolling out new services, allowing integration with existing applications. These new services will often be delivered through 
PORTAL - Institutional Portals - A Review of Outputs

institutional portals using portlet technology and emerging WS for Remote Portals standard." (McDonald, 2003) 


\section{Outcomes}

Whilst the outputs of institutional portal projects are frequently demonstrable the outcomes are less so but will, inevitably, become increasingly visible in the longer term. Both qualitative and quantitative measures will need to be applied to assess the value and impact of institutional portals in the longer term. Whilst a considerable number of authors have described their visions for institutional portal and fewer have described the outputs on their institutional portals deployments a more limited set still have illustrated the outcomes of their institutional projects.

\section{Evaluation}

Whilst far from a mainstream activity a number of institutions have begun to evaluate their portal deployments. Ehrmann provides a series of 'Notes on the Evaluation of Campus Portal Initiatives'and the results of a number of evaluations were available including reports from the University of Nottingham (Joyes, 2003) and the Santa Barbara City College (Campus Pipeline, 2002). Work package 13 of the PORTAL project will be focusing on the evaluation of institutional portals.

\section{Cost Saving and Efficiency}

Whilst for many institutional portals insufficient time has lapsed to effectively assess the cost saving and efficiency gains provided by institutional portals, it is also the case that a number of institutions are providing services both via a portal and via more traditional means. Despite these caveats there are indications that institutional portals may provide cost and efficiency savings. For George Washington University the deployment of the GWeb portal has reduced the costs associated with maintaining directory entries and reduced institutional paper usage (De Leo, 2002). Cobb, Riley and Earley (2002) indicated that whilst a room bookings system was the output of the early stages of their portal development work the fact the one employee was freed from manually taking room bookings allowed that employee to develop increased conference revenue for the institution.

Similarly, Oblinger \& Goldstein (2002) indicate the potential saving surrounding online purchasing and procurement procedures, for example the University of Pennsylvania estimates that current paper based procurement systems cost $\$ 150$ per item, the eprocurement system comes in at $\$ 10$. Similarly, they note that West Virginia Wesleyan College has moved to electronic application. The system has been implemented for an initial investment of $\$ 25,000$ for the first year and $\$ 15,000$ per year there after - under the previous paper based systems printing costs alone amounted to $\$ 30,000$ per year as applicants received an average 34 pieces of mail from enquiry to acceptance. Whilst 
such systems are not necessarily dependent on the existence of institutional portals such figures maybe indicative of the potential cost saving incurred via institutional portal deployments.

\section{Recruitment \& Retention}

In common with cost saving and efficiency gains it is, perhaps too soon to measure the effect of institutional portals in the areas of recruitment and retention. The experience of the University of Buffalo indicates that where institutional portals help tackle the causes of student drop out they have been effective in enabling retentions. The University has indicated that student retention has increased by $3 \%$ simply by providing access to student financial information and providing alerts to students who have outstanding balances. The reminder to settle accounts has prevented those students who may previously have had to abandon their studies due to unforeseen financial difficulties form doing so (Olsen, 2002).

\section{Consultation}

Englert (2003) indicates that all the institutions surveyed, in the Accenture research, had consulted current students and most had consulted with teaching staff. A good example of an institutional user requirement study has been produced by the University of Bristol (Agarwal \& Walker, 2002) and a general view of the stakeholder requirements for institutional portals has been produced as part of Work Package 3 of the PORTAL project.

The Accenture research indicated that of the 16 portal deploying institutions surveyed only 4 had meet their objectives with $60 \%$ indicating that their initial objectives had evolved in the last two years. Such a figure indicates the need for institutions to invest in ongoing stakeholder consultation and evaluation. Work Package 13 of the PORTAL project will be examining the issues surrounding the evaluation of institutional portals.

\section{Collaboration}

The need for portal development to take place across traditional institutional structure is highlighted by Cobb, Riley and Earley. Discussing the development of LSE for You they reflect on the fact that the:

"development process itself has a unifying aspect. New communication channels were introduced, and offices and service providers had to establish standards for sharing data and defining a lingua franca for the terminology" (2002)

Similarly a number of institutions have established cross departmental steering groups to guide portal development. At the University of Hull, for example, the portal deployment forms part of the Digital University Project which has working groups 
looking at transactional content group, portal implementation and authentication, authorisation and person profiling. The groups are comprised of relevant individuals from a range of departments. The bringing together of key groups and individuals within institutions has the potential to facilitate the sharing of skills and experiences across institutions.

Collaboration has not been limited to intra-institutional activities. Collaborative initiatives such as the Java Architectures Special Interest Group's open source portal, uPortal leveraging developer effort from a number of institutions world wide. The recently established JASIG UK ${ }^{28}$ provides a register of interests for those developing uPortal installations in order to facilitate collaboration.

The need for increased intra-institutional collaborative work and the decision of a number of institutions to work co-operatively on a national and international scale can only benefit the education community by provide forums for the dissemination of ideas and experiences.

${ }^{28}$ www.ja-sig.org.uk 


\section{Conclusions}

- The range of services and resources referenced within this review reflects the extent to which institutional portals have become a key tool in delivery of information and services in a number of institutions. Whilst North America is currently leading the development of institutional portals many UK universities are building on the early experiences of those institutions to create portals of their own.

- A number of writers indicate that institution wide support will be vital for the successful deployment of institutional portals. Whilst managing the relationships necessary for such buy-in will be the responsibility of the staff of individual institutions the dissemination of information via briefing papers and awareness raising events, by national agencies, may be beneficial to raising the profile of portal development within institutions.

- Daigle \& Cuocco (2002) indicate that institutional portals are not yet fully evolved.

"First generation portals emphasise content; second-generation portals focus on institutional processes, services, technology applications and, process integrations; third-generation portals will likely strive to integrate data, voice, and video on a variety of platforms (such as handheld computers) perhaps over wireless networks." (Daigle \& Cuocco, 2002:115)

A range of portal activities and approaches have been referenced in this review yet it is clear that the majority of institutional portals fall somewhere between first and second generation portal deployments.

- Whilst a range of institutions and portal features have been referenced in this review accessing information regarding the specifics of institutional portal developments was far from easy. Whilst a number institutions publish portal 'strategies', 'plans' or 'visions' a more limited number supply information regarding their achievements, works in progress and realistic further plans. In a rapidly developing area the ability to access information regarding the status or ease of development of various features would be beneficial to those developing institutional portals. Case studies, such as those provided by the London School of Economics, provide valuable insights into the issues surrounding the development of an institutional portal.

- Similarly, in the course of reviewing institutional portal sites the disparate provision of access to demonstration sites became clear. Sites such as My UW Madison and UD \& Me provide visitors with access to a version of their portal enabling interested parties to explore functionality, content and look and feel. The inclusion of tours or demonstration sites provides those seeking information and first hand experience of an institutional portal with a means to compare and evaluate developments. 
- If the community interest in institutional portals continues to develop at its current rate it will be vital for both institutions and the wider community to undertake work to assess both their short and long term value and impact. 


\section{References}

Awre, C. (2002). Portals and the JISC Information Environment Strategy. Portals 2002. www.nottingham.ac.uk/portals2002/ChrisAwre.ppt

Browning, P. (2003). Avoiding Portal Wars. Portals 2002. www.nottingham.ac.uk/portals2002/PaulBrowning.ppt

Browning, P. (2003) Portals and Portal Frameworks. http://www.bris.ac.uk/is/projects/portal/portalbytes\#list [Accessed 16/6/03]

Cobb, C., Riley, R. \& Earley, S. (2002). LSE for You: London School of Economic Portals Case Study. [online] http://www.Ise.ac.uk/collections/BSS/JISC_LSEforYou.pdf [accessed 15/11/02]

Connolly, C.G. (2000). From Static Web Site to Portal. Educause Quarterly 23 (2). [online] http://www.educause.edu/ir/library/pdf/eq/a002/eqm0024.pdf [accessed 15/11/02]

Daigle, S. L. \& Cuocco, P. M. (2002). 'Portal Technology Opportunities, Obstacles, and Options: A View from the California State University'. In: Katz, R.N. et al. Web Portals in Higher Education: Technologies to Make IT Personal. Jossey-Bass, San Fransisco.

De Leo, F (2002). The George Washington University Enterprise Portal Solution. http://www.gwu.edu/ imag/conf/02fall/conf_gweb.pdf [Accessed 18/5/03]

Dolphin, I \& Sherratt, R. (2002). The University of Hull Portal \& Process. Portals 2002. www.nottingham.ac.uk/portals2002/programme

EIS - University of Nottingham. (2002). Why Have a Portal at Nottingham? http://www.eis.nottingham.ac.uk/compass/whyportal.html [Accessed 18/5/03]

Eisler, D. Gilbert, S. \& Mehaffy, G. (2000) Provosts on Portals. http://old.weber.edu/portals/ [accessed 15/11/02]

Eisler, D. (2001). Campus Portals: Are We Ready? Connections 2001 - Centre for Curriculum, Transfer \& Technology May 7, 2001 - Whistler, British Columbia, Canada http://faculty.weber.edu/deisler/provost/connections2001/portals.doc

Ethridge, R.R, Hadden C. M., \& Smith, M. P. (2000). Building a Personalized:Get a behindthe-scenes look at LSU's award-winning system Education Portal, Educause Quarterly (3)

Englert, B, (2003). Portals Trends In Higher Education. Educause Southwest Regional Conference 2003. http://www.educause.edu/asp/doclib/abstract.asp?ID=SWR0304

Fleischman, J. (2002). Portals for Higher Education. Converge Magazine. October 2002. http://www.convergemag.com/magazine/story.phtml?id=29720

Frazee, J. (2001) SDSU Rubric for Rating Commercial Portal Vendors. http://its.sdsu.edu/portal_rubric.pdf

Gleason, B. (2002). Portal Technology Opportunities, Obstacles, and Options: A View from Boston College. In: Katz, R.N. et al. Web Portals in Higher Education: Technologies to Make IT Personal. http://www.educause.edu/ir/library/pdf/pub5006j.pdf

Grant, G.B \& Anderson, G. (2002). Customer Relationship Management: A Vision for Higher Education. In: Katz, R.N. et al. Web Portals in Higher Education: Technologies to Make IT Personal. http://www.educause.edu/ir/library/pdf/pub5006f.pdf

IBM. (2003). Portal Definition. www.3ibm.com/software/webservers/portal/whatis.html [Accessed 10/4/03]

JISC. (2002) JISC Information Environment Architecture Portal FAQ. http://www.ukoln.ac.uk/distributed-systems/jisc-ie/arch/faq/portal/ 
Jacobsen, C. (2000) 'Institutional Information Portals', Educause Review, July/August 2000. http://www.educause.edu/pub/er/erm00/articles004/horizons.pdf

Joyes, G. (2003). Evaluation report: COMPASS Portal February 2003. http://www.eis.nottingham.ac.uk/compass/resources/portal-eval-01-2003.pdf

Katz, R.N. (2002) 'It's a bird! It's a plane! It's a ...portal?' In: Katz, R.N. et al. Web Portals in Higher Education: Technologies to Make IT Personal. http://www.educause.edu/ir/library/pdf/EQM0038.pdf

Karpinski, R. (2002). Gartner Sees Major Growth in Middleware, Portals. Internet Week http://www.internetwk.com/story/INW20020625S0002/

Lightfoot, E \& Ihrig, W. (2002). Customer-Centered Resources. In: Katz, R.N. et al. Web Portals in Higher Education: Technologies to Make IT Personal. http://www.educause.edu/ir/library/pdf/pub5006e.pdfLittle, J. (2001). A Librarian's Perspective on Portals. Educause Quarterly (2)

Lorenzo, G. (2002). "Web Services Enabling Technology for Application Integration and Assembly" HEKATE http://www.hekate.org/HEKATEwebserviceswhitepaper.pdf

Looney, M. \& Lyman, P. (2000). Portals in Higher Education. Educause Review. July / August 2000. [online] http://www.educause.edu/pub/er/erm00/articles004/looney.pdf [accessed 15/11/02]

McCredie, J. (2002) Why You Need an Enterprise e-Strategy, Not Just a Portal http://uccsc.berkeley.edu/mccredie.html

Olsen, F. (2002). The Power of Portals. The Chronicle of Higher Education. 09/08/02. [online] http://chronicle.com/free/v48/i48/48a03201.htm [accessed 15/11/02].

Paadre, H \& King, S. Electronic Community and Portals. http://www.mis2.udel.edu/jasig/holycross.doc

Pickett, R.A. \& Hamre, W.B. (2002). Building Portals for Higher Education. New Directions for Institutional Research (113) Spring 2002

Regents of the University of California, (2001). 'My UCDavis: Serving us now, laying the foundations for the future enterprise portal'. UC Davis ITTimes. http://ittimes.ucdavis.edu/oct2001/myucd.html

Regents of the University of California, (2002). A New Business Architecture for the University of California. http://uc2010.edu/abuot/index.htm

Stanton, K. (2002). COMPASS : Building Support of an Integrated Community. Portals 2002, Nottingham. www.nottingham.ac.uk/portals2002/karenstanton.ppt

Strauss, H. (2002). All About Web Portals: A Home Page Doth Not a Portal Make, In: Katz, R.N. et al. Web Portals in Higher Education: Technologies to Make IT Personal. http://www.educause.edu/ir/library/pdf/pub5006g.pdf

Supple, D. (2003). The Portal Project at the University of Birmingham. Pan European Portals Conference 2003. http://www.codex-se.org/pepc2003/pres/supple.ppt

Walsh, J .F. \& Thomas, J. (2002). The Enterprise Portal as a Service Delivery Framework, Educause 2002 Atlanta, Georgia http://www.educause.edu/asp/doclib/abstract.asp?ID=EDU0295 
PORTAL - Institutional Portals - A Review of Outputs 